\title{
Expressed breast milk on a neonatal unit: A hazard analysis and critical control points approach
}

Veerle Cossey, MD, ${ }^{\mathrm{a}, \mathrm{b}}$ Axel Jeurissen, MD, PhD, ${ }^{\mathrm{b}, \mathrm{c}}$ Marie-José Thelissen, ${ }^{\mathrm{b}}$ Chris Vanhole, MD, PhD, ${ }^{\mathrm{a}}$ and Annette Schuermans, MD, $\mathrm{PhD}^{\mathrm{b}}$

Leuven and Wilrijk, Belgium

\begin{abstract}
With the increasing use of human milk and growing evidence of the benefits of mother's milk for preterm and ill newborns, guidelines to ensure its quality and safety are an important part of daily practice in neonatal intensive care units. Operating procedures based on hazard analysis and critical control points can standardize the handling of mother's expressed milk, thereby improving nutrition and minimizing the risk of breast milk-induced infection in susceptible newborns. Because breast milk is not sterile, microorganisms can multiply when the milk is not handled properly. Additional exogenous contamination should be prevented. Strict hygiene and careful temperature and time control are important during the expression, collection, transport, storage, and feeding of maternal milk. In contrast to formula milk, no legal standards exist for the use of expressed maternal milk. The need for additional measures, such as bacteriological screening or heat treatment, remains unresolved.

Key Words: NICU; infection control; mother's milk; quality control.
\end{abstract}

Copyright ( $(2011$ by the Association for Professionals in Infection Control and Epidemiology, Inc. Published by Elsevier Inc. All rights reserved. (Am J Infect Control 2011;:-1-7.)

Serious Enterobacter sakazakii infections reported in formula-fed preterm and term infants have led to the promulgation of guidelines for the preparation, storage, and handling of powdered infant formula in hospitals following the basic risk control principles of hazard analysis and critical control points (HACCP) to reduce the risk of infection. ${ }^{1,2}$ Legal criteria have been developed for the use of powdered formula milk for infants under 6 months of age. ${ }^{3}$ The implementation of these guidelines is mandatory and regulated by national food agencies.

Nonetheless, breast milk remains the preferred nutrition for all infants, including preterm and ill newborns, with rare exceptions. ${ }^{4}$ The beneficial effects of breast milk are related to improvements in host defense, absorption of specific nutrients, enteral tolerance, and neurodevelopmental outcome. Breast-feeding also enhances

From the Neonatal Intensive Care Unit ${ }^{\mathrm{a}}$ and Department of Hospital


and Microbiology Laboratory, Sint-Augustinus Hospital, Wilrijk, Belgium. ${ }^{c}$

Address correspondence to Veerle Cossey, MD, Department of Hospital Hygiene and Infection Control and Department of Neonatology, UZ Leuven, Herestraat 49, 3000 Leuven, Belgium. E-mail: veerle.cossey@ uzleuven.be.

Conflict of interest: None to report.

$0196-6553 / \$ 36.00$

Copyright (c) 2011 by the Association for Professionals in Infection Control and Epidemiology, Inc. Published by Elsevier Inc. All rights reserved.

doi:10.1016/j.ajic.2011.01.019 maternal involvement and mother-infant interaction and bonding, which can be compromised in the neonatal intensive care unit (NICU) setting. Efforts are underway worldwide to encourage and support mothers' milk feeding in the NICU. If direct breast-feeding is not possible, then expressed breast milk can be fed by nasogastric tube.

Mother's milk is not sterile and can be a vehicle for commensal and pathogenic microorganisms derived from the mother or the NICU environment. ${ }^{5,6}$ Human milk has the potential to carry infectious agents, occasionally causing late-onset sepsis, especially in preterm and very low birth weight infants. Transmission through breast milk of such pathogens as Staphylococcus aureus, group B streptococci, Eschericia coli, Pseudomonas spp, Klebsiella spp, Serratia spp, Salmonella spp, and cytomegalovirus have been documented. ${ }^{7-17}$ of greatest concern, and the most widely studied, is human immunodeficiency virus. ${ }^{18}$

Recommended good hygienic practices have been developed for the expression, collection, transport, storage, and optimal handling of human milk in a neonatal unit. These recommendations are intended to ensure that human milk is microbiologically safe and nutritionally and immunologically complete. In contrast to formula milk, no microbiological quality standards or specific state regulations are available for expressed breast milk used exclusively for a mother's own infant in a hospital.

The aim of the present study was to apply the principles of HACCP to standardize the handling of expressed breast milk at every stage and ensure the 
milk's quality and safety. Health care professionals and other caregivers need to pay attention to the risk for environmental contamination and to the cold chain management of breast milk.

\section{METHODS}

To apply the HACCP principles to the use of expressed breast milk in the hospital, a multidisciplinary team was formed consisting of an infection control doctor and nurse, a neonatologist, nurses from the neonatal unit, and ancillary and lactation staff members. The NICU is part of the Leuven University Hospital, which has earned the Baby-Friendly Hospital Initiative designation. Breast-feeding is promoted for the $>850$ infants admitted annually to the NICU.

\section{The HACCP process}

HACCP is a systematic preventive approach to identify, evaluate, and control significant hazards to food safety. The HACCP approach is aimed at unsafe practices during the entire processing and storage process and as such differs from traditional final product testing, such as bacteriological sampling. All steps are designed to limit the contamination of expressed breast milk by microorganisms and to prevent multiplication of organisms.

The HACCP process involves 4 steps. ${ }^{19,20}$ In step 1, the scope of the HACCP is described, from the expression of milk to the feeding of infants in the NICU. Step 2 involves identifying potential hazards for each process step. In step 3, control measures to eliminate or reduce each of the identified hazards to an acceptable level are defined. For each critical control point (CCP) considered to have a significant effect on overall hazard of the procedure, a critical limit is established based on current evidence. Finally, in step 4 a monitoring system for each CCP is established, and corrective actions for deviations from critical limits are devised. Documentation includes a written HACCP plan, CCP monitoring, and adjustments for deviations.

\section{Identification of CCPs}

Most data are adapted from the existing standards for powdered formula and guidelines for the operation of donor human milk banks. A literature search of the PubMed database was conducted. Searches of published research and policy documents were carried out, and references from selected articles and from reviews were screened for additional relevant articles.

\section{RESULTS}

Figure 1 presents a flow diagram showing the human milk processing and storage steps and equipment. Table 1 summarizes the HACCP plan, including

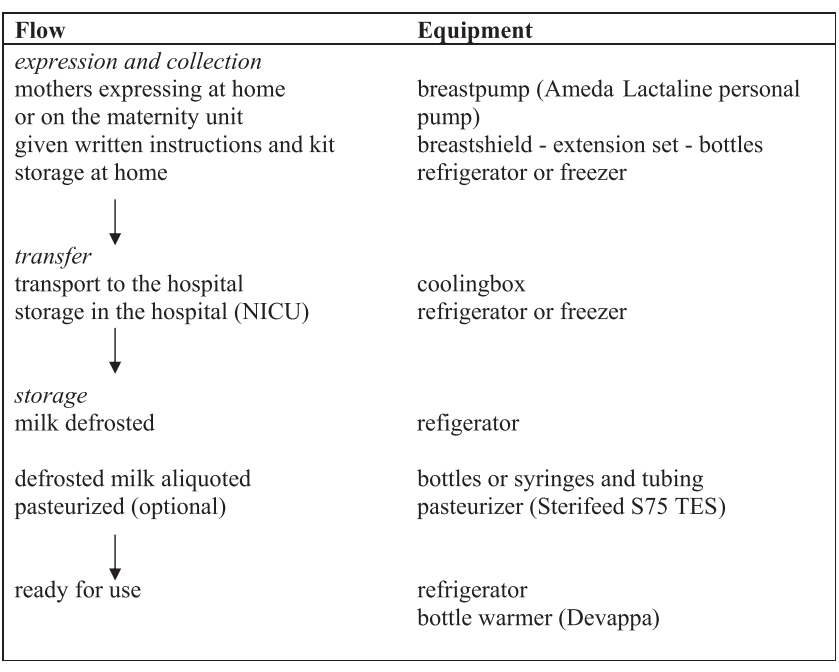

Fig I. The flow of the milk.

measurable indicators for use in monitoring the most important aspects of human milk expression, transport, delivery, storage, and administration. For all steps in the process, potential hazards, control measures, CCPs, and possible adjustments based on the level of concern are listed. ${ }^{21,22}$ At some NICUs, it has become routine to pasteurize mothers' own milk for feeding to susceptible infants. The most common procedure used is Holder pasteurization, in which the milk is heated to $62.5^{\circ} \mathrm{C}$ for 30 minutes. An HACCP-based plan indicating the potential hazards and CCPs during the pasteurization process is available from the authors on request. ${ }^{23-25}$

\section{DISCUSSION}

Interest in feeding human milk to preterm infants has increased during the past decade. The benefits of using a mother's own milk for her preterm infant outweigh any potential disadvantages. ${ }^{4}$ However, the use of expressed mother's milk mandates strict control of storage and handling in accordance with hygienic practices, given milk's potential as a vector for pathogens, especially when fed to immunologically vulnerable infants at high ambient temperatures.

When applying the HACCP principles to the management of expressed breast milk in a NICU, all steps of the process must be carefully analyzed. Because human milk is not sterile, each step in the collection and storage process can affect the final product. The identification of potential hazards implies considering the infant's susceptibility to infection and estimating the minimal infectious dose. CCPs should be defined based on clinical experience and limited evidence. If effective control options can be devised by implementation of 
infection control policies, then corrective actions can be identified if deviations occur.

\section{Hazard identification}

Does bacterial contamination of expressed breast milk really matter, and what level of contamination are we trying to avoid? Microbiological testing of expressed milk identifies bacterial growth in $>75 \%$ of samples, with $7 \%-36 \%$ of all samples containing pathogens. ${ }^{5,26,27}$ Some believe that the inherent antiinfective properties of the human milk are sufficiently strong to protect any infant under any conditions, including preterm infants in NICUs, and assume the best-case scenario when developing recommendations. ${ }^{28}$ However, the belief that expressed milk is safe even when containing pathogens is challenged by reports linking outbreaks and case reports of sepsis or necrotizing enterocolitis in NICUs to ingestion of contaminated human milk. ${ }^{5,29}$ This link is considered plausible, but clear evidence of causality is rarely based on molecular typing as proof of transmission. ${ }^{8,12,14,15}$

\section{Hazard characteristics}

It is not clear what effect different organisms and different levels of contamination of expressed milk have on recipient infants, and whether these effects differ according to the age or immune status of the consumer. Very little is known about the minimal infectious dose and how this varies in susceptible populations. For E sakazakii, even low-level contamination ( $<3 \mathrm{cfu} / 100 \mathrm{~g}$ ) is considered a risk factor given the potential for multiplication during the preparation and holding time before consumption. ${ }^{30}$ The risk of sepsis or necrotizing enterocolitis after ingestion of milk contaminated with even small inocula of microorganisms or microbial toxins is considered the greatest in very low birth weight neonates $(<1,500 \mathrm{~g})$ and those born at gestational age $<32$ weeks, who have limited transplacental transfer of antibodies and an immature intestinal mucosal immunity.

What is the risk that a feed that nearly always contains at least some organisms will lead to infection in the preterm neonate? During their first 2 weeks of feeding, neonates weighing $<2,000$ g showed surprisingly few adverse events of bacteremia and feeding intolerance that could be directly related to ingestion of bacteria in raw milk, with $10^{4.8} \pm 1.1 \mathrm{cfu}$ of gramnegative bacilli ingested per feed. ${ }^{5}$ Other investigators found a dose-response relationship, with feeding intolerance correlated with recovery of $\geq 10^{3} \mathrm{cfu}$ of gram-negative bacilli per $\mathrm{mL}$ of expressed milk and septic episodes correlated with recovery of $\geq 10^{6}$ $\mathrm{cfu} / \mathrm{mL}{ }^{27}$

\section{Storage conditions}

The recommended refrigerated storage time of 48 hours for expressed breast milk is based on studies showing no appreciable effect of refrigeration on bacterial growth for periods varying from 24 hours up to 8 days. ${ }^{31-33}$ Because regular opening of the refrigerator in the NICU does not guarantee a stable temperature at $4^{\circ} \mathrm{C}$, storage times exceeding 48 hours are not considered bacteriologically safe for use in the NICU. Human milk loses its bactericidal capacity when refrigerated for $>72$ hours. ${ }^{34-36}$

Temperature and time can be carefully monitored using the refrigerator logger with a probe placed in a bottle of water to indicate the core temperature. The environmental temperature in the inside of the refrigerator or shown on the display is indicative only of the core temperature. The critical limit of the core temperature is the value that should not be exceeded or else the milk must be discarded. Experimental studies of $E$ sakazakii in formula milk taking into account lag-phase and growth temperature have shown that a buffer zone of up to $7^{\circ} \mathrm{C}$ can be tolerated as long as the storage time at $5-7^{\circ} \mathrm{C}$ does not exceed 4 hours for reconstituted formula. ${ }^{37,38}$ A safety limit for human milk cannot be extrapolated from these data given the wide variety of microorganisms involved and the intrinsic bactericidal capacity of human milk. Most milk-associated bacteria will grow at $7-8^{\circ} \mathrm{C}$, however, so this seems to be an appropriate critical limit for preterm and ill infants. Because no minimal infectious dose is known, accurately specifying a safe time interval above this limit is difficult.

\section{Additional risk reduction strategies: To screen or to heat?}

By implementing the principles of HACCP listed in Table 1 to the daily practice of using expressed breast milk, the level of contamination can be reduced to acceptable standards and the growth of microorganisms before consumption can be minimized. Some CCPs are not yet completely defined and thus are not controllable, including a limit for total bacterial colony count per $\mathrm{mL}$ of milk and standards for the presence of skin commensals or specific pathogens. Although evidence-based steps and preventive measures cannot be applied, to further neutralize any microbial contamination, additional steps, such as microbiological testing and heat treatment, can be considered. These practices remain controversial issues in NICUs worldwide. $^{39,40}$

Mother's own milk cannot be subjected to the stringent microbiological standards applied to banked donor milk. ${ }^{41}$ Donated milk fed to a biologically unrelated 
Table I. HACCP plan for expressed breast milk

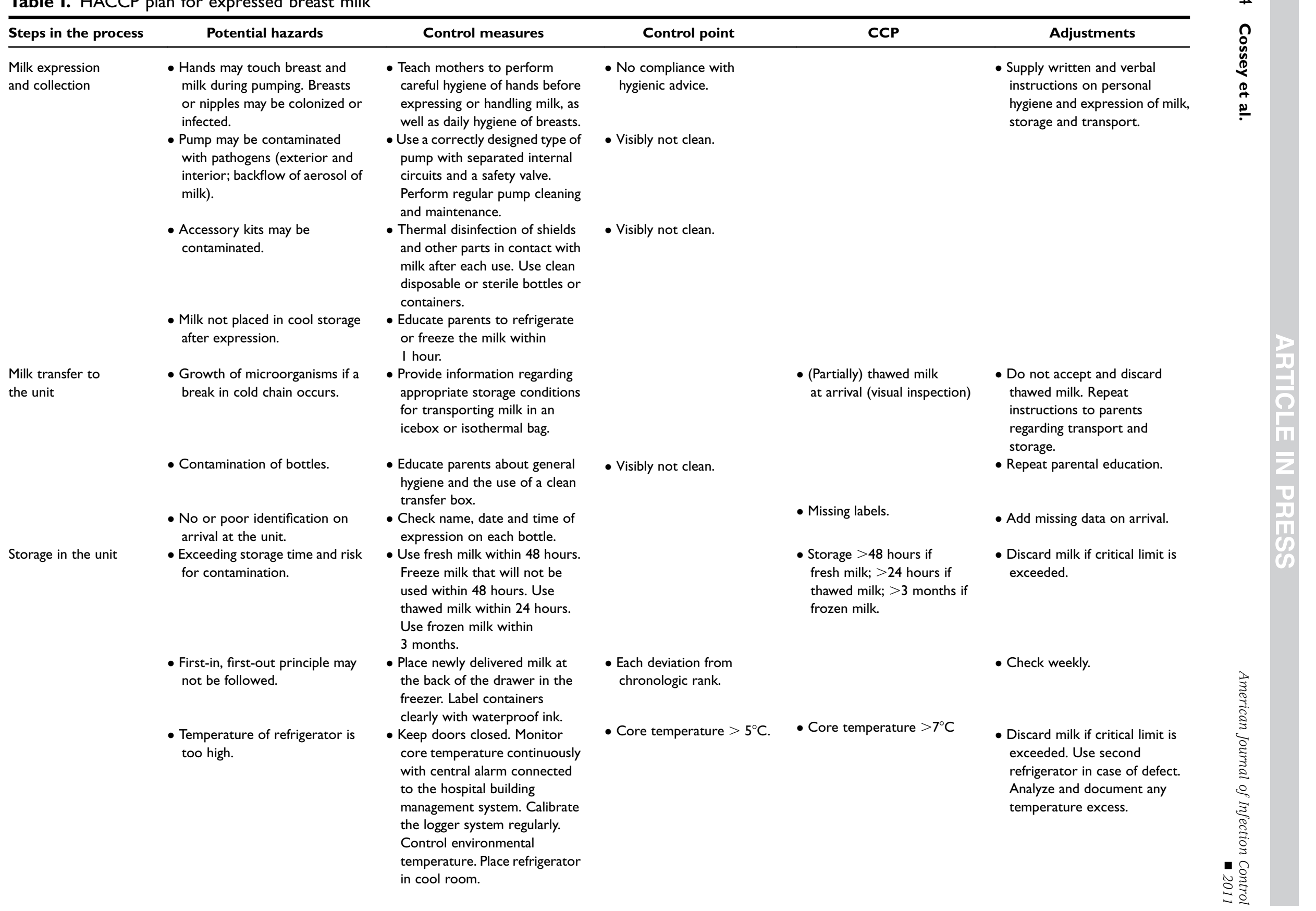


Preparation for use

- Temperature of freezer is too high.

- Other products or dirt in freezer or refrigerator may contaminate the milk.

- Exogenous contamination when dividing milk in aliquots.

- Bacterial growth at room temperature or during warming.

- External contamination of bottles during warming.

- Improper use of additives (eg, fortifiers).

- Expressed milk may be given to the wrong infant.

Keep doors closed. Monitor temperature continuously with central alarm connected to the hospital building management system. Clean and defrost periodically and wheneve visually contaminated.

- Keep a freezer and refrigerato in a secure room exclusively dedicated to milk. Clean daily.

- Clean surface and clean hands. Wear mask and cap. Do not handle formula milk when preparing maternal milk. Prepare individual feedings. Aliquot milk into sterile capped in refrigerator before use.

- Thaw frozen milk in refrigerator. Limit warming up time to $30 \mathrm{~min}$. Discard any milk from a partially consumed feeding, do not refrost or reheat.

- Use dry heating systems. Clean bottle warmer daily and when visually contaminated.

- Use capsules for individual use made under aseptic conditions and kept in dust-free container Use fortified milk ideally immediately or within 24 hours if refrigerated.

- Milk must be clearly labeled. Before feeding milk label and infant's ID should be doublechecked.

- Growth of microorganisms in expressed milk given as

- Change syringes or bottles every 4 hours and tubing every

24 hours.

continuous syringe or container and store

- $>$ I cm of ice or visibly not clean. Temperature $>-15^{\circ} \mathrm{C}$.

- (Partially) thawed milk

- Discard milk if partially defrosted. Analyze and document any temperature excess.

- Visibly not clean.

- No compliance with general hygiene

precautions. Caps and

masks not available. Task is

interrupted.

- Time between start of warming the milk and end of administration

$>$ I hour.

- Visibly not clean.
$>$ Expiration date of fortifier. $>24$ hours for fortified milk.

- Milk given to the wrong infant.

$->4$ hours hangtime
Simultaneous handling of mothers's milk and formula milk.

- Check expiration date. Discar milk with additives after 24 hours.

- Post-exposure protocol must be available in case of improper

- Discard milk if critical limit is exceeded.

Educate personnel.Organize divided preparations for mother's milk and formula milk.

Do not use milk if critical limit is exceeded. Educate health care providers. Document

temperature logging of bottle warmers. 
infant is either pasteurized before consumption or discarded if it contains $>10^{5} \mathrm{cfu} / \mathrm{mL}$ of total viable microorganisms or $>10^{4} \mathrm{cfu} / \mathrm{mL}$ of Enterobacteriaceae or $S$ aureus. $^{25}$ There are no universally accepted upper safe limits for bacterial concentrations in expressed breast milk given to the mother's own infant, and interpreting the results of milk cultures is difficult in the absence of appropriate standards. Testing milk can be useful when it is a suspected source of neonatal sepsis or feeding intolerance. Screening also ensures that the instructions for collection and transportation have been given, understood, and followed.

Those who believe that the number or type of bacterial contaminants ingested with milk can be assumed to affect the incidence and severity of illness, especially in preterm infants, should not attempt to define safe limits, but rather should consider not feeding raw expressed milk to high-risk infants. However, pasteurizing a mother's own milk for her infant will partly destroy the milk's unique immunologic protection. ${ }^{28,42}$ The process of heat treatment also leads to delays before consumption and extra costs.

In conclusion, the use of human milk in the NICU is not formally regulated under specific legislation as is formula. Thus, NICUs must be committed to the highest standards of self-regulation that are practically and scientifically warranted. The HACCP approach is an essential part of operational planning during milk management. If those caring for preterm infants wish to increase the proportion who receive the mother's own expressed breast milk, there needs to be agreement regarding the need for bacteriological screening of milk and the appropriate response to positive cultures or to the need for pasteurization.

\section{References}

I. Centers for Disease Control and Prevention. Enterobacter sakazakii infections associated with the use of powdered infant formula-Tennessee, 200I. MMWR Morb Mortal Wkly Rep 2002;51:297-300.

2. Agostoni C, Axelsson I, Goulet O, Koletzko B, Michaelsen K, Puntis J, et al. Preparation and handling of powdered infant formula: a commentary by the ESPGHAN Committee on Nutrition. J Pediatr Gastroenterol Nutr 2004:39:320-2.

3. European Commission (EC). Commission Regulation No. 2073/2005 of 15 November 2005 on microbiological criteria for foodstuffs. Official Journal of the European Union 2005;L338: I-26.

4. Gartner LM, Morton J, Lawrence RA, Naylor AJ, O'Hare D, Schanler $\mathrm{RJ}$, et al. American Acedemy of Pediatrics Section on Breastfeeding. Breastfeeding and the use of human milk. Pediatrics 2005; I 15:496-506.

5. Law BJ, Urias BA, Lertzman J, Robson D, Romance L. Is ingestion of milk-associated bacteria by premature infants fed raw human milk controlled by routine bacteriologic screening? J Clin Microbiol 1989; 27:1560-6.

6. Jones CA. Maternal transmission of infectious pathogens in breast milk. J Paediatr Child Health 2001;37:576-82.
7. Donowitz LG, Marsik FJ, Fisher KA, Wenzel RP. Contaminated breast milk: a source of Klebsiella bacteremia in a newborn intensive care unit. Rev Infect Dis 1981;3:716-20.

8. Gagneur A, Henry-Arnaud G, Croly-Labourdette S, Gremmo-Feger G, Vallet $S$, Sizun J, et al. Infected breast milk associated with late-onset and recurrent group B streptococcal infection in neonatal twins: a genetic analysis. Eur J Pediatr 2009; 168: I I55-8.

9. Godambe S, Shah PS, Shah V. Breast milk as a source of late-onset neonatal sepsis. Pediatr Infect Dis J 2005;24:38I-2.

10. Gransden WR, Webster M, French GL, Phillips I. An outbreak of Serratia marcescens transmitted by contaminated breast pumps in a special care baby unit. J Hosp Infect 1986;7:149-54.

II. Gras-Le GC, Lepelletier D, Debillon T, Gournay V, Espaze E, Roze JC. Contamination of a milk bank pasteuriser causing a Pseudomonas aeruginosa outbreak in a neonatal intensive care unit. Arch Dis Child Fetal Neonatal Ed 2003;88:F434-5.

12. Mammina C, Di Carlo P, Cipolla D, et al. Nosocomial colonization due to imipenem-resistant Pseudomonas aeruginosa epidemiologically linked to breast milk feeding in a neonatal intensive care unit. Acta Pharmacol Sin 2008;29:1486-92.

13. Olver WJ, Bond DW, Boswell TC, Watkin SL. Neonatal group B streptococcal disease associated with infected breast milk. Arch Dis Child Fetal Neonatal Ed 2000;83:F48-9.

14. Qutaishat SS, Stemper ME, Spencer SK, et al. Transmission of Salmonella enterica serotype typhimurium DTI04 to infants thourough mother's breast milk. Pediatrics 2003; I I I:1442-6.

15. Wang LY, Chen CT, Liu WH, Wang YH. Recurrent neonatal group B streptococcal disease associated with infected breast milk. Clin Pediatr 2007;46:547-9.

16. Youssef RF, Darcy E, Barone A, Borja MT, Leggiadro RJ. Expressed breast milk as a source of neonatal sepsis. Pediatr Infect Dis J 2002; 21:888-9.

17. Novak FR, Da Silva AV, Hagler AN, Figueiredo AM. Contamination of expressed human breast milk with an epidemic multiresistant Staphylococcus aureus clone. J Med Microbiol 2000;49:1 109-17.

18. Van de Perre P, Simonon A, Msellati P, et al. Postnatal transmission of human immunodeficiency virus type I from mother to infant: a prospective cohort study in Kigali, Rwanda. N Engl J Med 199|;325:593-8.

19. Hunter PR. Application of hazard analysis critical control point (HACCP) to the handling of expressed breast milk on a neonatal unit. J Hosp Infect 1991;17:139-46.

20. Codex Alimentarius Commission. Guidelines for the application of the hazard analysis critical control point (HACCP) system (CAC/GL 18-1993). Rome: Food and Agriculture Organization of the United Nations; 1995. p. 21-30.

2I. Jones F, Tully M. Best practice for expressing, storing, and handling human milk in hospitals, homes and child care settings. Raleigh (NC): Human Milk Bank Association of North America (HMBANA); 2005.

22. Lawrence RA. Breastfeeding: a guide for the medical profession. 6th ed. St Louis: Mosby; 2005. p. 629-94.

23. United Kingdom Association for Milk Banking. Guidelines for the establishment and operation of human milk banks in the UK. 3rd ed. London: Royal College of Paediatrics and Child Health; 2003.

24. Human Milk Banking Association of North America. Guidelines for the establishment and operation of a donor human milk bank. Sandwich (MA): HMBANA; 2005.

25. National Institute for Health and Clinical Excellence. Donor breast milk banks: the operation of donor breast milk bank services. London. Clinical guideline CG93. 20I0. Available from: http://guidance.nice.org .uk/CG93. Accessed March 17, 2011.

26. Ng DK, Lee SY, Leung LC, Wong SF, Ho JC. Bacteriological screening of expressed breast milk revealed a high rate of bacterial contamination in Chinese women. J Hosp Infect 2004;58: 146-50. 
27. Botsford KB. Gram-negative bacilli in human milk feedings: quantitation and clinical consequences for premature infants. J Pediatr 1986; 109:707-10.

28. Arnold L. Human milk in the NICU: policy into practice. Sudbury (MA): Jones \& Bartlett; 2010. p. 147-56.

29. Ng PC, Lewindon PJ, Siu YK, Wong W, Cheung KL, Liu K. Bacterialcontaminated breast milk and necrotizing enterocolitis in preterm twins. J Hosp Infect 1995;31:105-10.

30. Codex Alimentarius Commission. Code of hygienic practice for foods for infants and children. CAC/RCP 21-1979. Rome: Food and Agriculture Organization of the United Nations; 1994.

31. Pardou A, Serruys E, Mascart-Lemone F, Dramaix M, Vis HL. Human milk banking: influence of storage processes and of bacterial contamination on some milk constituents. Biol Neonate 1994;65:302-9.

32. Pittard WB. Bacteriostatic qualities of human milk. J Pediatr 1985; 107 : 240-3.

33. Sosa R, Barness L. Bacterial growth in refrigerated human milk. Am J Dis Child 1987; 141:1II-2.

34. Martinez-Costa C, Silvestre MD, Lopez MC, Plaza A, Miranda M, Guijarro R. Effects of refrigeration on the bactericidal activity of human milk: a preliminary study. J Pediatr Gastr Nutr 2007;45: 275-7.
35. Ogundele MO. Effects of storage on the physicochemical and antibacterial properties of human milk. Br J Biomed Sci 2002;59: 205-II.

36. Silvestre D, Lopez MC, March L, Plaza A, Martinez-Costa C. Bactericidal activity of human milk: stability during storage. $\mathrm{Br} J$ Biomed Sci 2006;63:59-62.

37. Gurtler JB, Beuchat LR. Growth of Enterobacter sakazakii in reconstituted infant formula as affected by coomposition and temperature. J Food Prot 2007;70:2095-103.

38. Iversen C, Lane M, Forsythe SJ. The growth profile, thermotolerance and biofilm formation of Enterobacter sakazakii grown in infant formula milk. Lett Appl Microbiol 2004;38:378-82.

39. Omarsdottir S, Casper C, Akerman A, Polberger S, Vanpee M. Breast milk handling routines for preterm infants in Sweden: a national crosssectional study. Breastfeed Med 2008;3:165-70.

40. Shetty A, Barnes R, Adappa R, Doherty C. Quality control of expressed breast milk. J Hosp Infect 2006;62:253-4.

4I. Hodge D, Puntis JW. The use of expressed breast milk for the premature newborn. Clin Nutr 2000;19:75-7.

42. Cossey V, Jeurissen A, Bossuyt X, Schuermans A. Effect of pasteurisation on the mannose-lectin activity and the concentration of soluble CDI4 in human milk. J Hosp Infect 2009;73:96-7. 